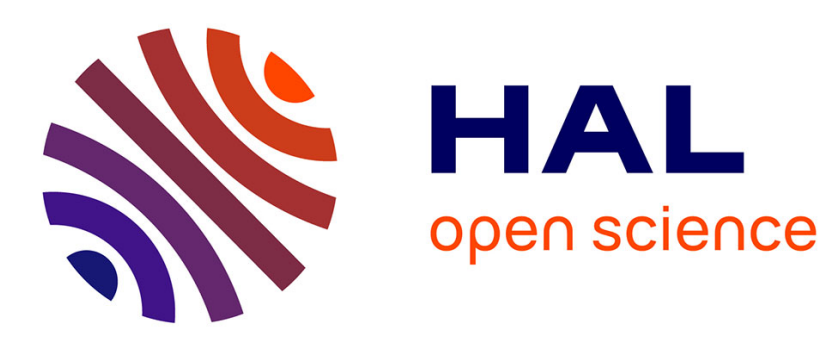

\title{
Magnetism and internal stresses : Concept of magneto-plastic anisotropy
}

Olivier Hubert, Michel Clavel, Ivan Guillot, Eric Hug

\section{To cite this version:}

Olivier Hubert, Michel Clavel, Ivan Guillot, Eric Hug. Magnetism and internal stresses: Concept of magneto-plastic anisotropy. Journal de Physique IV Proceedings, 1999, 09 (PR9), pp.Pr9-207 Pr9-216. 10.1051/jp4:1999921 . hal-01560783

\section{HAL Id: hal-01560783 https://hal.science/hal-01560783}

Submitted on 11 Jul 2017

HAL is a multi-disciplinary open access archive for the deposit and dissemination of scientific research documents, whether they are published or not. The documents may come from teaching and research institutions in France or abroad, or from public or private research centers.
L'archive ouverte pluridisciplinaire HAL, est destinée au dépôt et à la diffusion de documents scientifiques de niveau recherche, publiés ou non, émanant des établissements d'enseignement et de recherche français ou étrangers, des laboratoires publics ou privés. 


\title{
MAGNETISM AND INTERNAL STRESSES : CONCEPT OF MAGNETO- PLASTIC ANISOTROPY
}

\author{
O. Hubert, M. Clavel, I. Guillot, E. Hug \\ LG2mS, UPRESA CNRS 6066 - Université de Technologie de Compiègne \\ Centre de Recherches de Royallieu, BP20529, 60205 COMPIEGNE Cedex FRANCE
}

\begin{abstract}
This paper deals with the influence of plastic strains and correlated internal stresses on the magnetic properties of a nonoriented $3 \% \mathrm{Si}-\mathrm{Fe}$ alloy. We first studied the mechanical behaviour of the material and evaluated the internal stresses which occur with the strengthening. The alloy exhibits an isotropic mechanical behaviour and three stages of straining. The internal stresses are evidenced thanks to tensile / compressive tests: a high initial increase followed by a gradual one is observed. The internal stresses are linked to the drop of stress at the first stages of the deformation and to the heterogeneous structures of dislocations at higher plastic strain levels. The effect of the internal stresses on the magnetic properties is then discussed. A suitable magnetic frame has been manufactured. Magnetic characteristics are investigated along either the tensile or cross directions. The magnetic properties strongly decrease from the beginning of the plastic strain. Crossing experiments indicate an attenuated effect of the plastic strain on the magnetic properties compared to the colinear measurements. This directionnal effect, called "magnetoplastic anisotropy" seems to be directly linked to the internal stresses.
\end{abstract}

\section{INTRODUCTION}

The prediction of total energy losses in magnetic media for the manufacture of transformers and rotating electrical machines requires a numerical approach. To this end, standard magnetic characteristics of the material need to be known with high precision. These standard tests are generally implemented with laminated sheets previously annealed after cutting. Yet, it has been shown that total energy losses measured on electrical machines are sometimes twice or more higher than losses measured with standard frames. These differences can result from electromagnetic factors like waveform, harmonics and rotationnal fields, and from mechanical factors linked to the plastic strains which occur after manufacturing. In particular, it has been shown that manufacturing electrical steel sheets leads to the generation of a strong gradient of plastic strain in the neighbourhood of the cutting edge (Fig.1a) [1]. An experimental magnetic frame used to carry out the magnetic properties of tensile strained specimens has been developped to evaluate the influence of the plastic strain on the magnetic properties [2]. It was shown that the plastic strain drastically deteriorates the magnetic properties of on a nonoriented (NO) $3 \% \mathrm{Si}$ - Fe ferromagnetic alloy. A strong degradation of the magnetization curve is for instance observed especially in the range of low plastic strain level and for low and medium magnetic field amplitudes (Fig.1b).

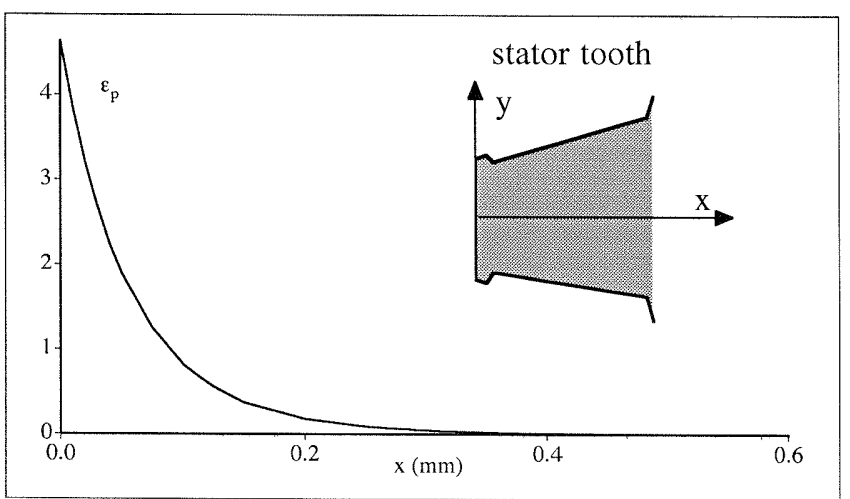

a)

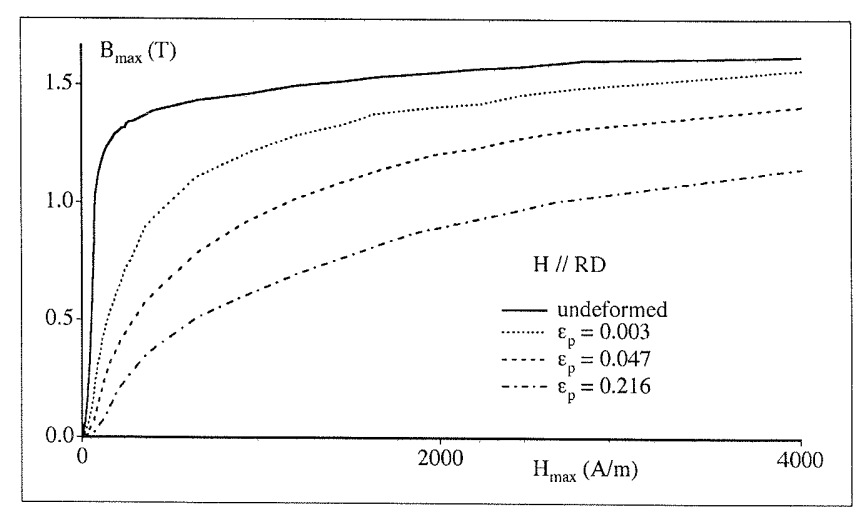

b)

Figure 1: (a) Gradient of plastic strain close to the cutting edge of a stator tooth [1], (b) influence of plastic strain on the magnetization curve [2]. 
On the other hand, previous mechanical tests showed that a tensile plastic strain is associated with the generation of internal stresses [3], meaning that elastic tension and compression areas are present in the metal die after unloading. The aim of this work is to quantify the internal stresses and to illustrate their influence on the magnetic properties. The internal stresses could in fact have an anisotropic influence on the magnetic properties because of the tensor character of the elastic fields of stress.

The general experimental procedure is explained in the first part. A new magnetic frame which has been especially manufactured for this experiment is described. Mechanical tests and metallurgical features are gathered in the second part. The magnetic measurements can be found in the third part. The results are finally discussed in the fourth part where the concept of magnetoplastic anisotropy is introduced.

\section{EXPERIMENTAL PROCEDURE}

\subsection{Mechanical analysis}

Experiments have been performed on a fully process $\mathrm{NO} 3 \% \mathrm{Si}$-Fe sheet $(0.5 \mathrm{~mm}$ thick). Tensile tests have been conducted on previously annealed specimens $\left(720^{\circ} \mathrm{C}\right.$ for $\left.2 \mathrm{~h}, \mathrm{P}\left(\mathrm{O}_{2}\right)=0.027 \mathrm{~Pa}\right)$ which consist of 200 $\mathrm{mm}$ long and $20 \mathrm{~mm}$ wide bands. They have been plastically deformed at different strain levels up to striction, at room temperature and a constant strain rate $\left(\mathrm{d} / \mathrm{dt}=1.3310^{-3} \mathrm{~s}^{-1}\right)$. Tensile tests have been carried out in the rolling (RD) and tranverse (TD) directions of the sheet plane in order to evaluate the initial mechanical anisotropy of the material. The features of the grains and dislocations after straining have been observed using optical techniques and transmission electronic microscopy (TEM) [4].

\subsection{Magnetic measurements}

Magnetic measurements are performed on samples $\left(20 \times 20 \mathrm{~mm}^{2}\right)$ which have been cut from the unstrained laminations and from the middle of the tensile test specimens. The experimental frame is composed of two ferrimagnetic "E" yokes positionned vertically and face to face (Fig. 2a). It allows to measure the magnetic characteristics of strained specimens both in the strengthening and cross directions (i.e. at $0^{\circ}$ and $90^{\circ}$ of the tensile direction). Two samples taken from the same tensile specimen and identically adjusted are put between the yokes in order to create an appropriate circulation of the field lines (Fig. 2b).

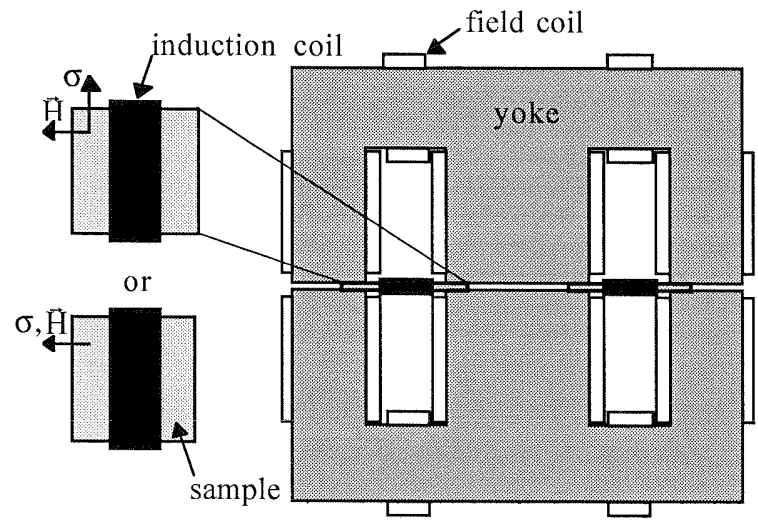

a)

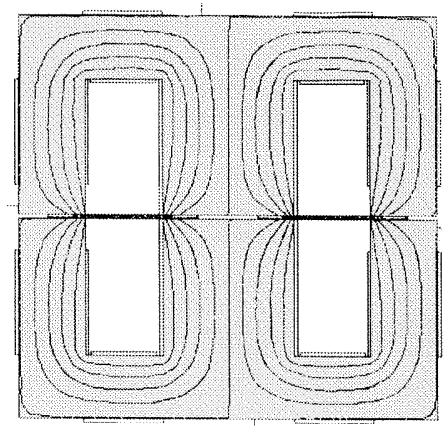

b)

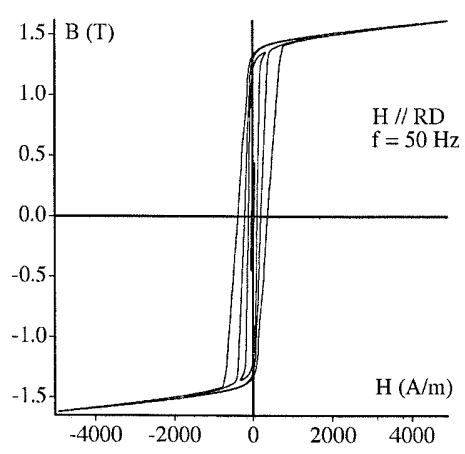

c)

Figure 2: (a) General view of the magnetic frame and samples. (b) Maxwell $2 \mathrm{D}^{\circledast}$ modelisation of the field lines for a magnetic field strength of $5000 \mathrm{~A} / \mathrm{m}$ in the samples, (c) various obtained $\mathrm{B}(\mathrm{H})$ hyteresis loops (unstrained sample, $\mathrm{f}=50 \mathrm{~Hz}$ ).

The field coils are wound round the ferrimagnetic yokes. A quasistatic excitation (sinusoidal field strength with $\mathrm{f}=0.1 \mathrm{~Hz}$ ) and a $50 \mathrm{~Hz}$ sinusoidal field have been used. Induction coils produce an electromotive force $\mathrm{u}(\mathrm{t})$ due to the rate of magnetic flux inside the samples. This electromotive force and the excitation current $i(t)$ signals are stored and are used to produce increasing hysteresis loops giving the magnetic flux density $\mathrm{B}(\mathrm{t})$ as a function of the magnetic field strength $\mathrm{H}(\mathrm{t})$ (Fig. 2c). Details of the calculations are explained elsewhere [4].

The magnetic characteristics reported in this paper are the magnetization and energy loss curves. The magnetization curve consists of the various $\left(\mathrm{B}_{\max }, \mathrm{H}_{\max }\right)$ points obtained for each hysteresis loop. The area 
of the hysteresis loop gives the total energy losses W. It is drawn as function of $\mathrm{B}_{\max }$. Quasistatic experiments allow us to determine the main hysteretic parameters: hysteresis losses $\mathrm{W}_{\mathrm{h}}$ and coercive field strength $\mathrm{H}_{\mathrm{c}}$. Using the hypothesis of the separation of the losses [5], the dynamic energy losses for $\mathrm{f}=50 \mathrm{~Hz}$ are extracted from $\mathrm{W}_{\mathrm{d}}=\mathrm{W}_{\mathrm{t}}-\mathrm{W}_{\mathrm{h}}$ with $\mathrm{W}_{\mathrm{t}}$ the total energy loss per cycle at this frequency. Both frequencies are used to reach the magnetization curve. The magnetic parameters are implemented successively for RD and TD after a tensile test along one of these directions in order to measure the magnetic anisotropy after the plastic straining. It means that four families of measurements are made for each plastic strain level, and crossing experiments $(\sigma \perp \overrightarrow{\mathrm{H}})$ are compared with colinear experiments $(\sigma / / \overrightarrow{\mathrm{H}})$.

\section{MECHANICAL BEHAYIOUR}

\subsection{Unstrained material}

The unstrained NO 3\% Si-Fe material has a recrystallized structure with no geometrical grain texture in the sheet plane (Fig. 3a). The grain size is heterogeneous with a mean value of $75 \mu \mathrm{m}$. Pole figures exhibit a weak $\{111\}<211>$ texture along $\mathrm{RD}$, characteristic of a recrystallized state after cold rolling. TEM observations show isolated $\{110\}$ a/ $2<111>$ screw dislocations (Fig. $3 b$ ). The initial dislocation density $\rho_{0}$, calculated using the Smith and Guthman method [3], is around $10^{9} \mathrm{~cm} / \mathrm{cm}^{3}$.

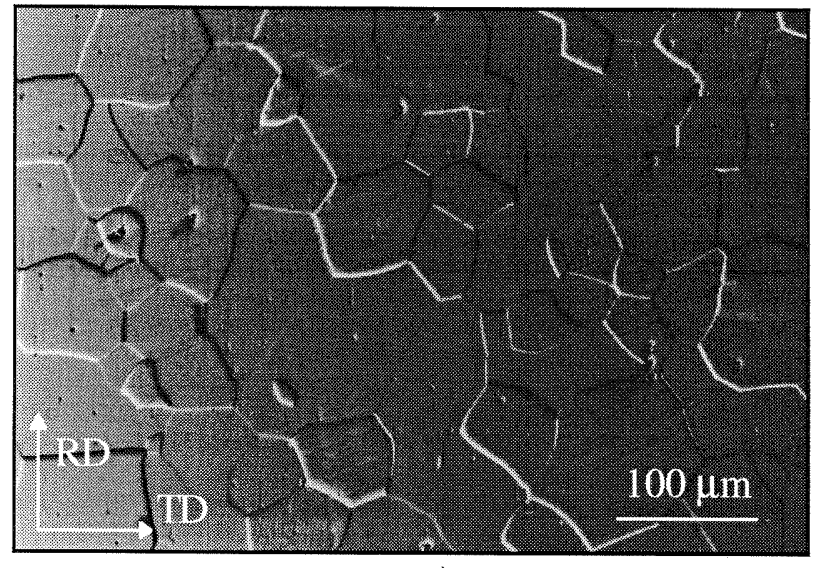

a)

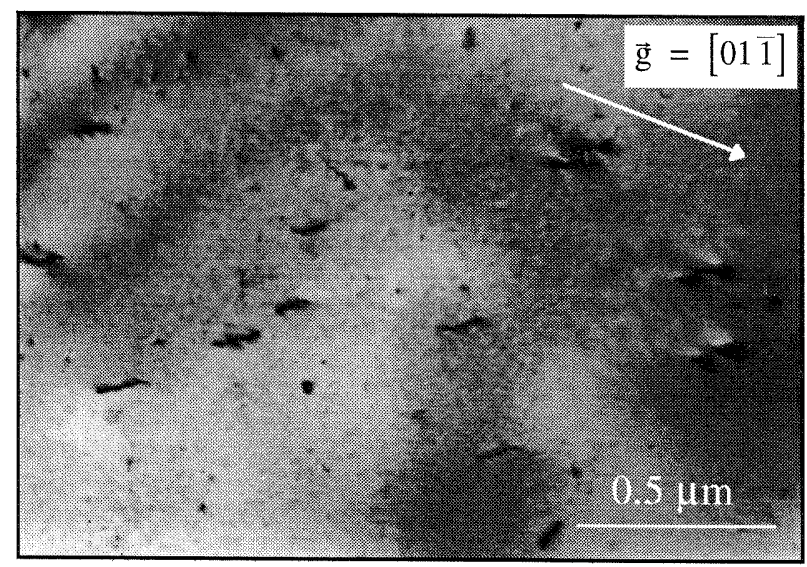

b)

Figure 3: Optical and TEM observations of the initial grain structure (a) and dislocation density (b).

\subsection{Tensile behaviour and metallurgical features}

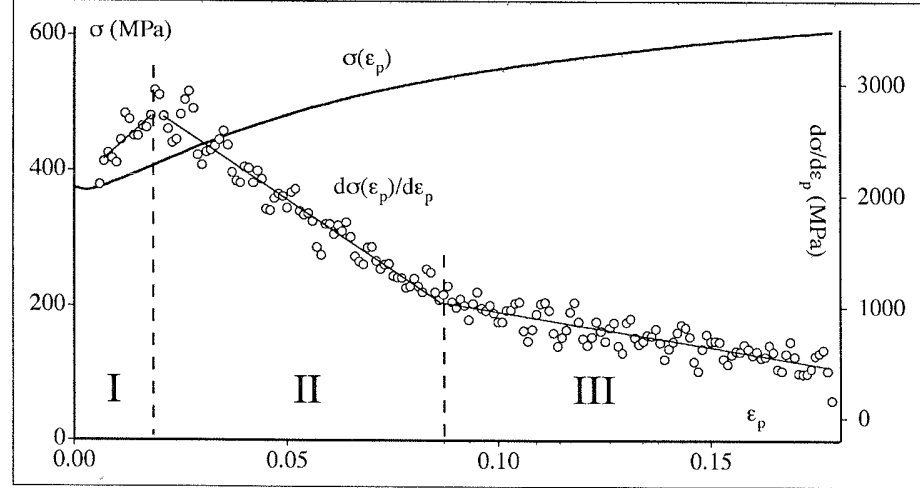

a)

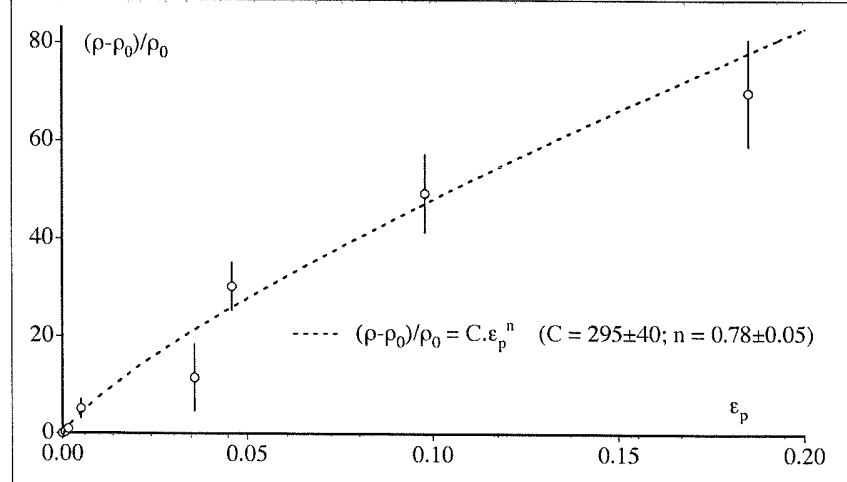

b)

Figure 4: (a) Tensile test $\sigma\left(\varepsilon_{\mathrm{p}}\right)$ for RD and linked rate of strengthening evolution in three stages, (b) relative variation of the dislocation density $\rho$ versus plastic strain.

The tensile curve of the material exhibits a weak stress drop $\left(\Delta \sigma_{\mathrm{e}}=5 \mathrm{MPa}\right)$ at the first stages of the plastic deformation immediatly followed by a classic strengthening (Fig. 4a). The stress drop is usually associated in the body centered cubic metals such as ferritic steels to the Lüders strain state which is an heterogeneous propagation of a plastically deformed zone [6]. In our case, stress remains constant on a very short strain range $\left(\Delta \varepsilon_{\mathrm{p}}^{\text {cte }}<0.002\right)$. Moreover $\Delta \varepsilon_{\mathrm{p}}^{\text {cte }}$ is identical for higher strain rate while the stress drop and yield 
stress increase. This stress drop is consequently not a Lüders strain state. The plastic deformation begins in the best oriented grains and is macroscopically homogeneous. Further analysis [4] show that it seems to be associated to the drop in the shear stress related to the unpinning of the dislocations from the Cottrell's atmospheres [6]. On the other hand the mechanical behaviour of the alloy is isotropic in the sheet plane (maximal variation $\Delta \sigma$ is less than $30 \mathrm{MPa}$ whatever the tensile test direction and strain level) and three stages of straining are demonstrated plotting the strengthening rate $\mathrm{d} \sigma / \mathrm{d} \varepsilon_{\mathrm{p}}=\mathrm{f}\left(\varepsilon_{\mathrm{p}}\right)$ curve (Fig. 4a). Stage I is a transitional stage linked to the stress drop. The strengthening rate decreases linearly during stage II. Stage III begins around $\varepsilon_{\mathrm{p}}=0.08$ which may correspond to a transition in the plastic strain mechanisms.

Optical and TEM observations have been conducted at different strain levels corresponding to the main previously defined strengthening stages (Fig. 5). The observed dislocation features at various plastic strain level are well known and the dislocation density evolution is classic (Fig. 4b) [6]. For the weak plastic strain $\left(\varepsilon_{\mathrm{p}}=0-0.005\right)$, fine slip lines appear in some randomly distributed grains of the tensile test specimen. This confirms that plasticity is macroscopically homogeneous during the stress drop. The substructure is composed of long screw dislocations with some cusps showing that more than one slip system are activated. Their distribution is homogeneous in the grains even if the dislocation density is sometimes higher at the grain boundaries. Multiple slip gives rise to debris which are in form of small or elongated loops created behind the jogged screw dislocations. The multiple slip causes slip lines to progressively vanish at higher plastic strain levels $\left(\varepsilon_{p}=0.01-0.03\right)$. The first to second stage transition corresponds to the appearance of numerous small clusters of bowing dislocations and debris. The density of debris in the clusters increases with plastic strain causing the substructure to become increasingly heterogeneous. The second to third stage transition $\left(\varepsilon_{\mathrm{p}}=0.08-0.1\right)$ corresponds to the arrangement of clusters in bundles, then in cell walls of dislocations generally composed of dislocation loops with primary Bürgers vector. They are separated by regions of relatively low dislocation density. Optical observations show the simultaneous appearance of thick and wavy glide bands in the most deformed grains. The dislocation substructure does not really change up to striction $\left(\varepsilon_{\mathrm{p}}=0.185\right)$. The density of dislocations decreases in the channel while it increases inside the bundles and cells walls. Heterogeneous character of the substructure is more pronounced. The grains are elongated in the direction of the applied stress and the wavy bands have a strongly contrasted aspect.

\subsection{Measurement of the internal stresses}

The plastic straining of the NO 3\% Si-Fe is associated with the generation of strain heterogeneities which are able to create internal stresses. Their measurement which requires tensile-compressive tests is nevertheless difficult because of the overly fine thickness of the tensile test specimens. Suitable samples cut from a thicker hot-rolled 3\% SiFe alloy ( $3 \mathrm{~mm}$ thick) have consequently been used [4]. They have been heat treated in order to exhibit the same mechanical behaviour as the $0.5 \mathrm{~mm}$ thick material. The same experimental conditions (strain rate, temperature) than for the tensile tests have been used. Some tensile / compressive test curves are shown in figure $6 \mathrm{a}$ for various imposed plastic strain levels $\varepsilon_{\mathrm{pi}}$. They have been conducted in the rolling direction. The total applied stress $\sigma$ may be expressed using the equation (1), where $\sigma_{\mathrm{e}}$ is the initial yield stress, $\mathrm{R}$ the isotropic and $\mathrm{X}$ the kinematic components of the strengthening (Fig. $6 \mathrm{~b}$ ). The kinematic strengthening $X$ evolution is representative of the internal stresses, $\left(R+\sigma_{e}\right)$ is the effective stress $\sigma_{\text {eff }} . \mathrm{R}$ and $\mathrm{X}$ evolution during the tensile test are computed using a Lemaitre-Chaboche model [7].

$$
\sigma=\sigma_{\mathrm{e}}+\mathrm{R}+\mathrm{X}=\sigma_{\text {eff }}+\mathrm{X} \text { with } \mathrm{R}=\mathrm{R}_{1}+\mathrm{R}_{2} \text { and } \mathrm{X}=\mathrm{X}_{1}+\mathrm{X}_{2}+\mathrm{X}_{3}
$$

$R$ is written as the sum of a decreasing and an increasing isotropic components: $R_{1}$ and $R_{2}(2,4,5)$. The kinematic component of the strengthening $\mathrm{X}$ is the sum of two non-linear and one linear components $\mathrm{X}_{1}, \mathrm{X}_{2}$ and $\mathrm{X}_{3}(3,6,7,8)$. Parameters have been numerically determined (Table 1) thanks to SiDoLo program [8] to model the tensile test behaviour along RD and TD (Fig. 7). The model gives a good account of the experimental results. The internal stress $\mathrm{X}$ exhibits a high initial increase immediatly followed by a gradual one.

$$
\begin{gathered}
\mathrm{R}_{1}=\mathrm{q}_{\mathrm{r} 1} \cdot\left(1-\exp ^{\frac{-\varepsilon_{\mathrm{pcum}}}{\mathrm{b}_{\mathrm{r} 1}}}\right), \mathrm{R}_{2}=\mathrm{q}_{\mathrm{r} 2} \cdot\left(1-\exp ^{\frac{-\varepsilon_{\mathrm{pcum}}}{\mathrm{b}_{\mathrm{r} 2}}}\right) \\
\frac{\mathrm{dX} \mathrm{X}_{1}}{\mathrm{dt}}=\left(\mathrm{C}_{\mathrm{x} 1}-\gamma_{\mathrm{s} 1} \mathrm{X}_{1}\right) \cdot \frac{\mathrm{d} \varepsilon_{\mathrm{p}}}{\mathrm{dt}}, \frac{\mathrm{dX} \mathrm{X}_{2}}{\mathrm{dt}}=\left(\mathrm{C}_{\mathrm{x} 2}-\gamma_{\mathrm{s} 2} \mathrm{X}_{2}\right) \cdot \frac{\mathrm{d} \varepsilon_{\mathrm{p}}}{\mathrm{dt}}, \frac{\mathrm{dX} \mathrm{X}_{3}}{\mathrm{dt}}=\mathrm{C}_{\mathrm{x} 3} \cdot \frac{\mathrm{d} \varepsilon_{\mathrm{p}}}{\mathrm{dt}} \\
\text { with } \varepsilon_{\mathrm{p}}=\varepsilon-\varepsilon_{\mathrm{e}}=\varepsilon-\frac{\sigma}{\mathrm{E}}, \varepsilon_{\mathrm{pcum}}=\int\left|\mathrm{d} \varepsilon_{\mathrm{p}}\right|
\end{gathered}
$$



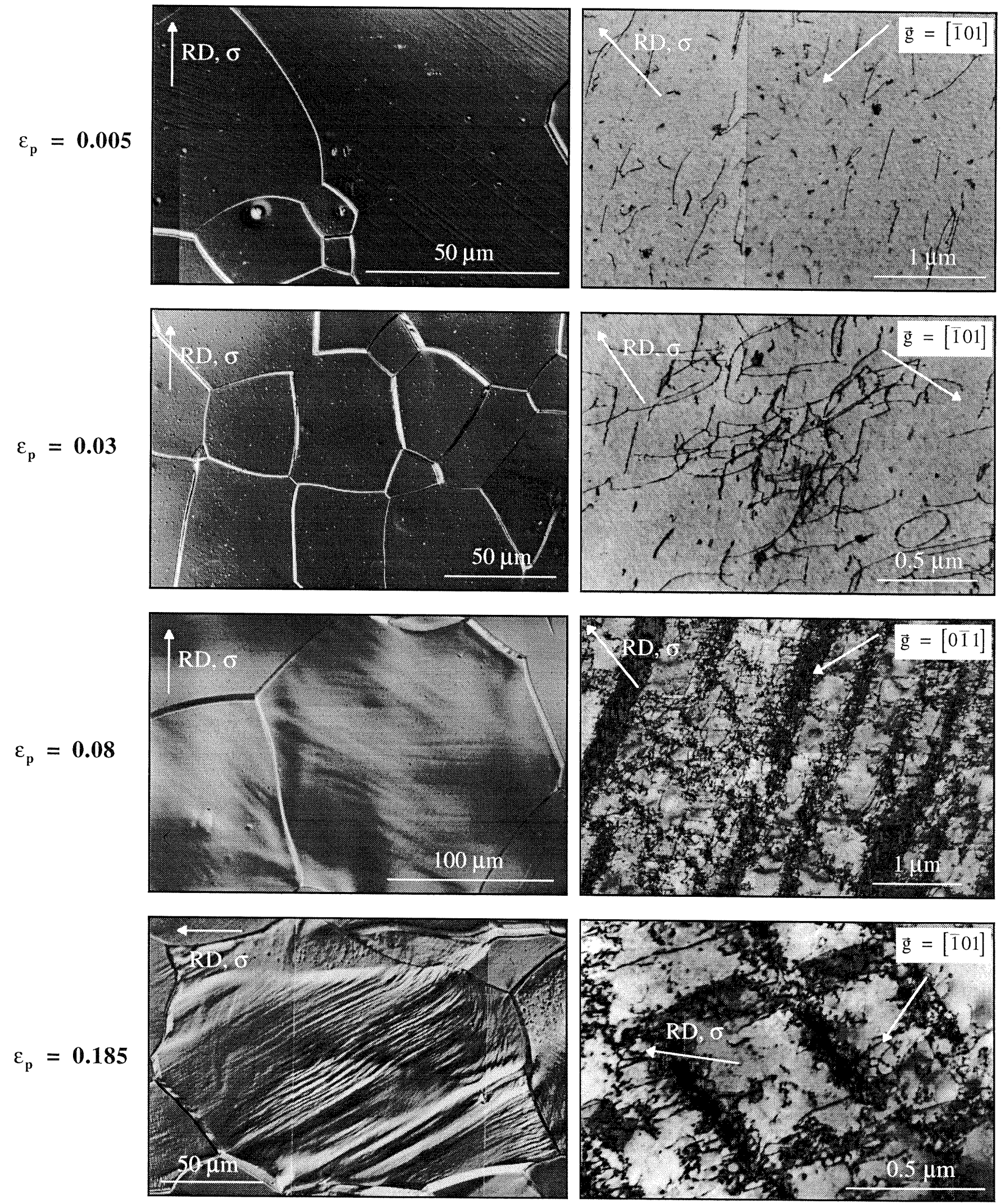

Figure 5: Grain and dislocation features at various plastic strain levels corresponding to the main microstructural transitions. 


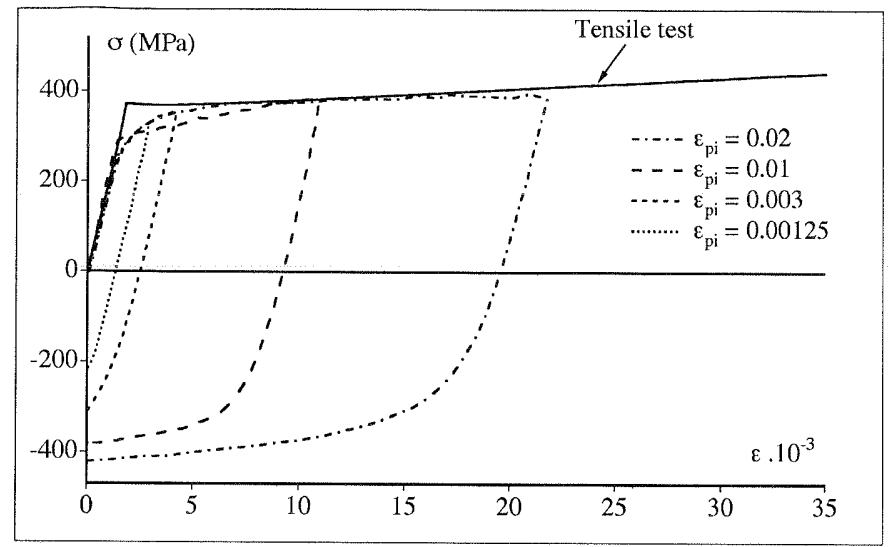

a)

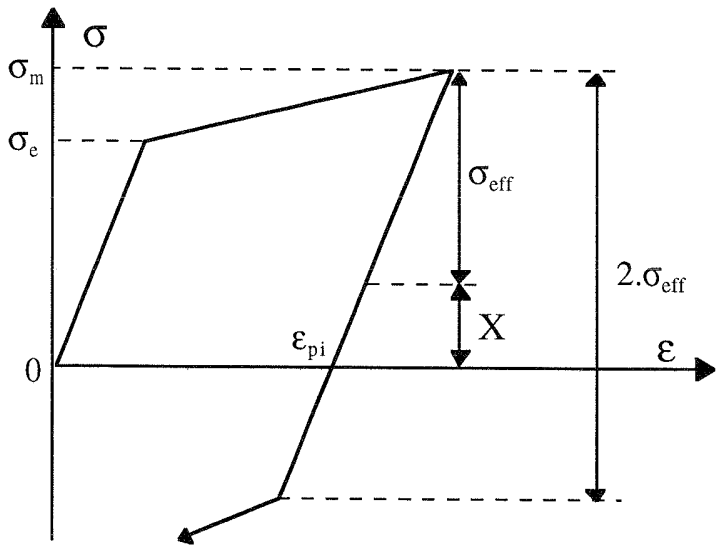

b)

Figure 6: (a) Various experimental tensile / compressive tests compared with the tensile test curve, (b) determination of the effective $\left(\sigma_{\text {eff }}\right)$ and kinematic $(\mathrm{X})$ components of the strengthening.

Table 1: Parameters of the Lemaître-Chaboche model for RD and TD.

\begin{tabular}{|c|c|}
\hline Young's modulus E (MPa) & 195200 \\
\hline Poisson's coefficient $v$ & 0.33 \\
\hline$\sigma_{s}(\mathrm{MPa}) \mathrm{RD} / \mathrm{TD}$ & $282 / 308$ \\
\hline$C_{x 1}$ & 132000 \\
\hline$\gamma_{\text {sI }}$ & 1630 \\
\hline (n) & 1980 \\
\hline$Y_{s 2}$ & 30 \\
\hline$C_{\times 3}$ & 291 \\
\hline $\mathrm{q}_{\mathrm{r}}(\mathrm{MPa})$ & -26 \\
\hline $\mathrm{b}_{\mathrm{n}}$ & 0.0061 \\
\hline $\mathrm{q}_{2}(\mathrm{MPa})$ & 206 \\
\hline$b_{12}$ & 0.104 \\
\hline
\end{tabular}

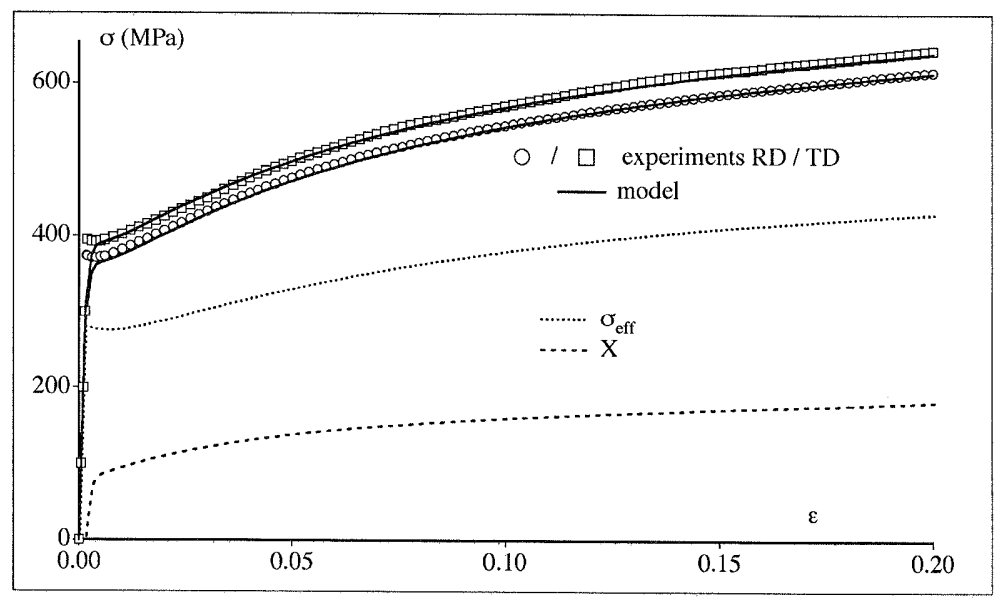

Figure 7: Modelling of the tensile test for RD and TD. Coupled evolution of $\mathrm{X}$ and $\sigma_{\text {eff }}$ for RD.

\section{MAGNETIC MEASUREMENTS}

\subsection{Unstrained material: initial magnetic behaviour}

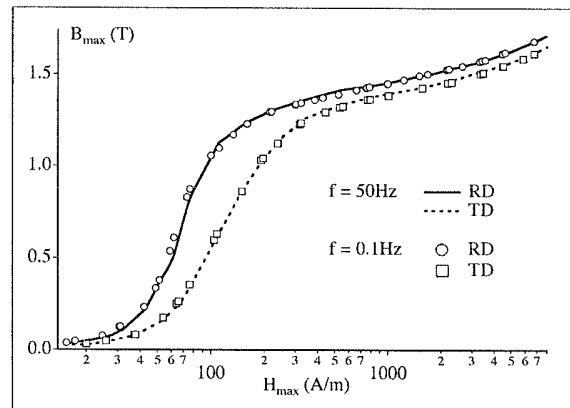

a)

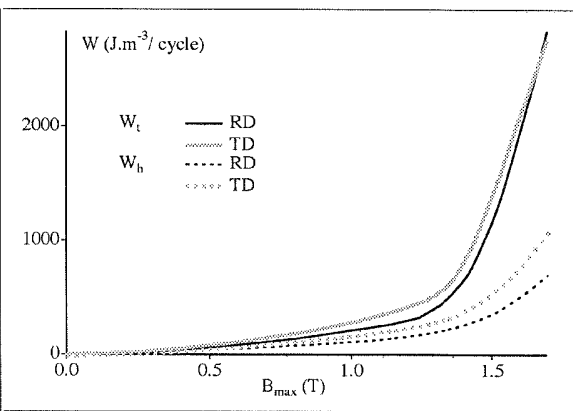

b)

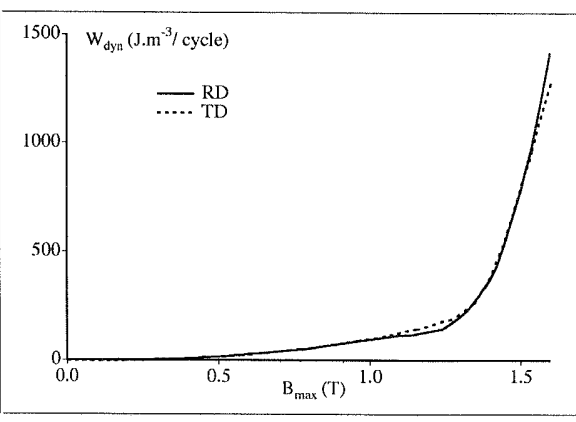

c)

Figure 8: Magnetization curves $(f=50 \mathrm{~Hz}$ and $0.1 \mathrm{~Hz})(\mathrm{a})$, total energy $(f=50 \mathrm{~Hz})$ and hysteresis losses $(f=0.1 \mathrm{~Hz})(\mathrm{b})$, and dynamic losses (c) along RD and TD.

The magnetic behaviour of the material is studied along RD and TD. The magnetization curves are the same for the both frequencies (Fig. 8a). The magnetic properties are affected by an initial anisotropy as shown by the magnetization curves (Fig. 8a) and coercive field strength $\left(\mathrm{H}_{c}(\mathrm{RD})=47 \mathrm{~A} / \mathrm{m}_{1} \mathrm{H}_{\mathrm{c}}(\mathrm{TD})=70 \mathrm{~A} / \mathrm{m}\right)$. The magnetic behaviour is better along RD than along TD. This difference has a crystallographic origin [9]. The total energy and hysteresis loss curves show the same tendancy (Fig. 8b). The dynamic losses curves for both directions exhibit the same behaviour (Fig. 8c). The gap of $\mathrm{W}_{\mathrm{t}}$ is consequently mainly due to the difference between the hysteresis losses from one direction to the other. 


\subsection{Colinear measurements: influence of the plastic strain}

Tensile tests have been carried out along $\mathrm{RD}$ and $\mathrm{TD}$ at various plastic strain levels corresponding to the main transitions which occur during the strengthening: $\varepsilon_{\mathrm{p}}=0.005 / 0.036 / 0.098 / 0.185$. A straight degradation of the magnetic properties is observed. Figures $9 \mathrm{a}$ and $9 \mathrm{~b}$ show the evolution with $\varepsilon_{\mathrm{p}}$ of the hysteresis loops and energy losses for $\mathrm{f}=50 \mathrm{~Hz}$ along RD. Figure $9 \mathrm{c}$ shows on the other hand that the magnetic degradation is identical for RD and TD. This degradation is very strong from the first stages of the plastic strain and especially sensitive for the weak and medium field strength (i.e. $0<\mathrm{H}_{\max }<2000 \mathrm{~A} / \mathrm{m}$ ). Strong increases of the coercive field strength (Table 2) and hysteresis losses are observed too.

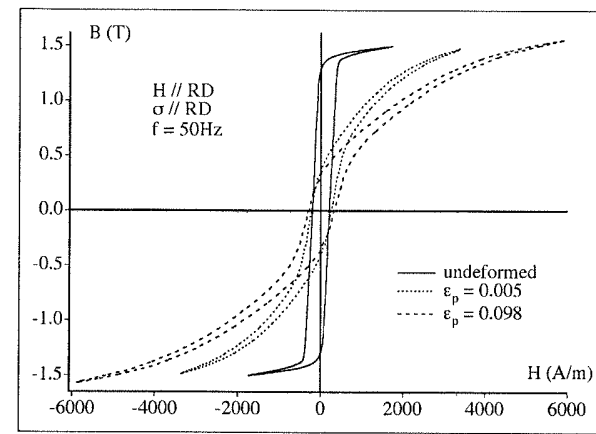

a)

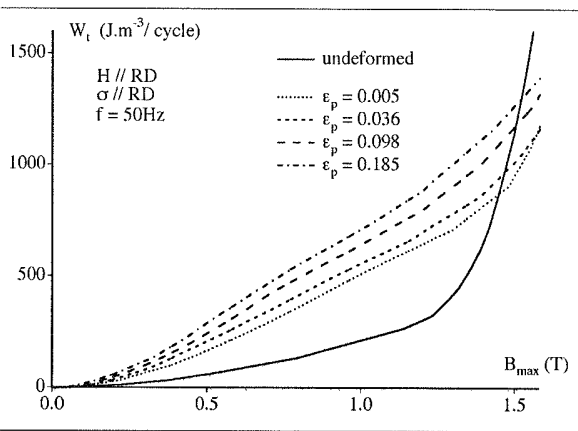

b)

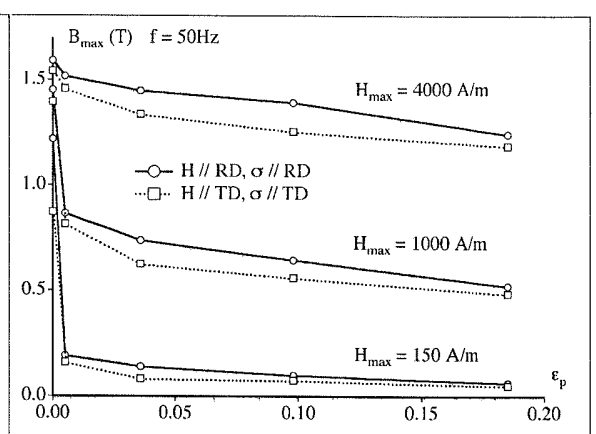

c)

Figure 9: Evolution of the hysteresis loops (a), $\mathrm{W}_{t}(\mathrm{~b})$, and $\mathrm{B}_{\max }$ for various $\mathrm{H}_{\max }$ (c) with plastic strain $(\mathrm{f}=50 \mathrm{~Hz})$.

The effect of the plastic strain on $\mathrm{W}_{\mathrm{t}}$ is singular for $\mathrm{B}_{\max }>1.4 \mathrm{~T}$. A crossing of the different $\mathrm{W}_{\mathrm{t}}\left(\mathrm{B}_{\max }\right)$ characteristics is observed in figure $9 \mathrm{~b}$ : plastic strains induce a decrease of the total energy losses for the high magnetic induction levels. This behaviour is mainly linked to the progressive change of $B(t)$ waveform. $\mathrm{B}(\mathrm{t})$ waveform is initially trapezoidal and becomes progressively sinusoidal with plastic strain. High frequencies harmonics and dynamic losses consequently decrease [4],[9]. The variation of the three kinds of energy losses is reported in figure 10 for $\varepsilon_{p}=0.036$. The main part of total energy losses is linked to the variation of the hysteresis losses for $\mathrm{B}_{\max }<1.3 \mathrm{~T}$. The strong decrease of the dynamic losses for $\mathrm{B}_{\max }>1.4 \mathrm{~T}$ is due to the change of the induction waveform. The decrease of the dynamic losses is on the other hand linked to the increase of the electrical resistivity of the material with the plastic strain [10], and the result decrease of the eddy currents, as it has been previously observed by C. Hou [11]. This decrease can be also partly explained taking into account the pinning of the domain walls on the increasing number of metallurgical defects (dislocations, clusters and walls). The changes in magnetic flux produce less eddy current losses in the strained samples because the metallurgical defects lead to more magnetic domain walls moving smaller distance [12].

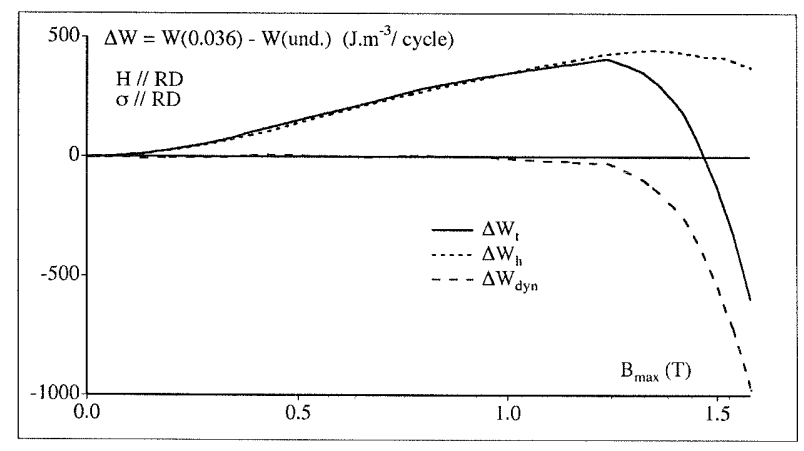

Table 2: Coercive field strength along RD and TD (A/m).

\begin{tabular}{|c|c|c|c|c|c|c|}
\hline \multirow{2}{*}{$\frac{\overrightarrow{\mathrm{H}} / /}{\mathrm{RD}}$} & $\vec{\sigma} / /$ & $\overline{\text { undef }}$ & $\varepsilon_{\mathrm{p}}=0.0$ & $\overline{0.036}$ & $\overline{0.098}$ & 0.185 \\
\hline & RD & 47 & 135 & 172 & 202 & 234 \\
\hline & T1 & 47 & 105 & 130 & $" 162$ & 200 \\
\hline \multirow[t]{2}{*}{ TD } & TD & 70 & 148 & 188 & 224 & 265 \\
\hline & RD & 70 & 125 & 154 & 185 & 217 \\
\hline
\end{tabular}

Figure 10: Variation of the three kinds of energy losses for $\varepsilon_{\mathrm{p}}=0.036$ along RD.

\subsection{Cross measurements: influence of the internal stresses}

Cross measurements have been carried out for the four previous levels of plastic deformation. They all indicate that the degradation of the cross behaviour $(\vec{\sigma} \perp \overrightarrow{\mathrm{H}})$ due to the plastic strain is less pronounced than the degradation in the colinear direction $(\vec{\sigma} / / \overrightarrow{\mathrm{H}})$. The changes in magnetization are shown in figure 11 for $\varepsilon_{\mathrm{p}}=0.036$ and a magnetic measurement along RD (Fig. 11a) or along TD (Fig. 11b). The phenomenon appears for the magnetic measurements along both directions, but the range is weaker along TD. It is on the other hand shown that the difference between cross and colinear behaviour decreases to zero with increasing 
magnetic field strength. The total energy and hysteresis losses exhibit the same behaviour (Fig. 11c). Moreover the evolution of the hysteresis losses with this directionnal effect is very close to the total energy losses and the dynamic losses are not modified. The coercive field strength is as well function of the direction of the applied stress (table 2). The directionnal effect, generated by the plastic strain, may consequently be defined as a "magnetoplastic anisotropy", probably linked to the internal stresses.

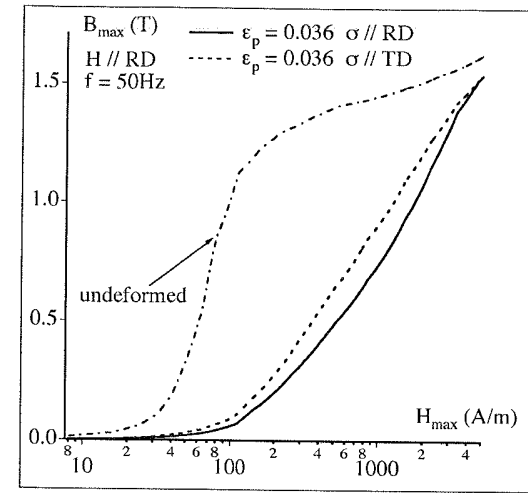

a)

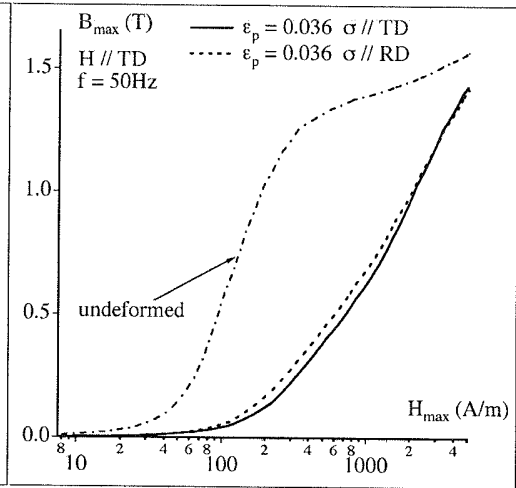

b)

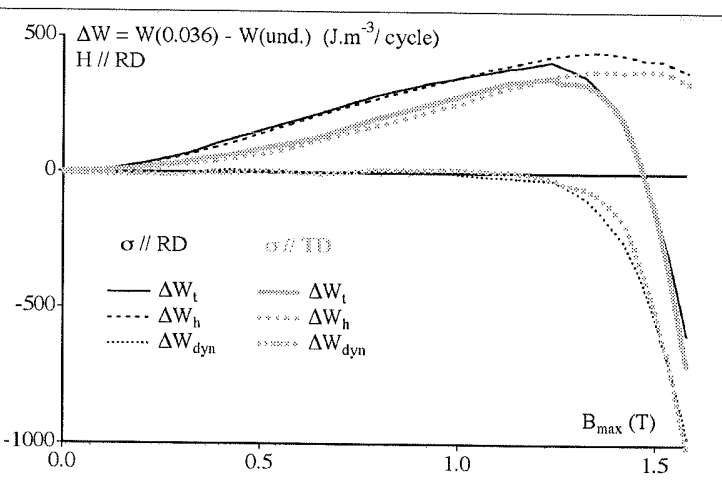

c)

Figure 11: Effect of the direction of the applied stress on the magnetization curves along RD (a) or along TD (b), and on the variation of the different kinds of energy losses along $\mathrm{RD}(\mathrm{c})$ for $\varepsilon_{\mathrm{p}}=0.036$.

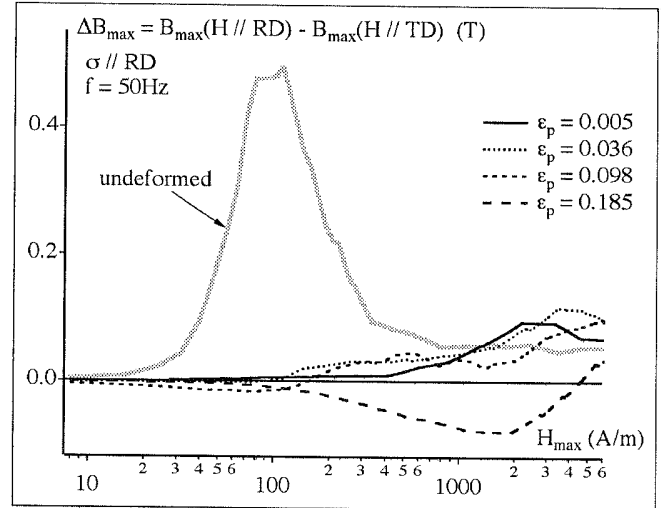

a)

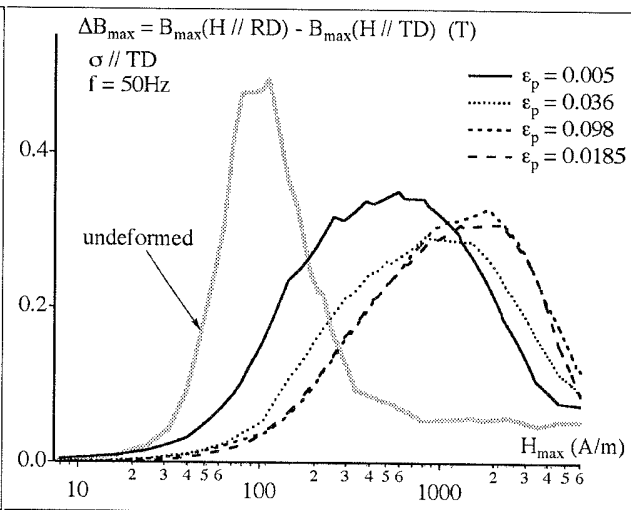

b)

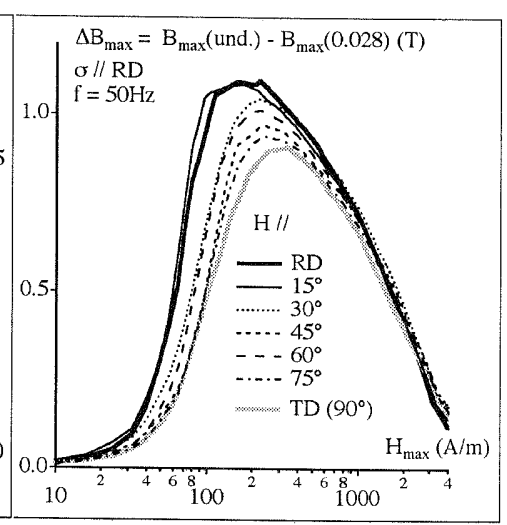

c)

Figure 12: Variation of induction between RD and TD after a tensile test along RD (a) or along TD (b). (c) Variation of induction in different magnetic measurement directions before and after a plastic strain $\varepsilon_{\mathrm{p}}=0.028$ applied along RD.

Figure $12 \mathrm{a}$ and $12 \mathrm{~b}$ show the $\left(\Delta \mathrm{B}_{\max }\left(\mathrm{H}_{\max }\right)=\mathrm{B}_{\max }(\overrightarrow{\mathrm{H}} / / \mathrm{RD})-\mathrm{B}_{\max }(\overrightarrow{\mathrm{H}} / / \mathrm{TD})\right)$ characteristics at the different plastic deformation levels after a tensile test conducted along $R D$ or TD. The maximal variation is relatively constant for the both tensile test directions whatever the plastic strain level, but the increasing plastic strain induces a translatory motion of the curves to the higher magnetic field strength levels. Magnetic measurements in other directions round off these results: figure $12 \mathrm{c}$ shows the $\left(\Delta \mathrm{B}_{\max }\left(\mathrm{H}_{\max }\right)=\right.$ $\mathrm{B}_{\max }\left(\varepsilon_{\mathrm{p}}=0\right)-\mathrm{B}_{\max }\left(\varepsilon_{\mathrm{p}}=0.028\right.$ along RD)) with a magnetic measurement along each $15^{\circ}$ direction between RD and TD. The maximal variation appears for the colinear measurement i.e. for $\vec{H} / / \mathrm{RD}$ and the minimal variation for the cross measurement $(\vec{H} / / \mathrm{TD})$. A continuous transition is also observed between these two directions. This experiment shows that the magnetoplastic anisotropy is a continouous phenomenon between two principles directions which are the tensile and cross directions.

\section{DISCUSSION AND CONCLUSION}

\subsection{Origin and distribution of the internal stresses}

The tensile plastic strain of the alloy is associated with the generation of two scales of heterogeneities. The first stage of the tensile test straining is characterized by a drop of stress related to the unpinning of the dislocations from the Cottrell's atmospheres. This phenomenon is thought to be at the origin of high intergranular stresses linked to the strain incompatibilities at grain boundaries. Heterogeneous structures of dislocations are produced at higher plastic strain levels: small clusters at the beginning of the second stage, 
then bundles and cells during the third stage. These structures promote an increasing intragranular stress. Its value can be numerically determined using the composite model of Mughrabi [13], which gives the macroscopic shear stress $\tau_{\text {macro }}$ as function of the behaviour of both soft and hard phases (11). Equation (12) gives therefore the intragranular internal shear stress expression. The classic formula (13) expresses on the other hand the shear stress of the hard and soft phases as function of the dislocation density inside each phase [13]. Considering that the strain is homogeneous at higher scale, the intragranular stress expression can be given by equation (14) [14].

$$
\tau_{\text {macro }}=\mathrm{f}_{\mathrm{h}} \cdot \tau_{\mathrm{h}}+\mathrm{f}_{\mathrm{s}} \cdot \tau_{\mathrm{s}}, \tau_{\text {intra }}=\tau_{\text {macro }}-\tau_{\mathrm{s}}=\mathrm{f}_{\mathrm{h}} \cdot\left(\tau_{\mathrm{h}}-\tau_{\mathrm{s}}\right)
$$

$\tau_{\mathrm{h}}, \tau_{\mathrm{s}}$ : shear stress of the hard (clusters, bundles..) and soft (matrix) phases

$\mathrm{f}_{\mathrm{h}}, \mathrm{f}_{\mathrm{s}}$ : volume fractions of the two phases $\left(\mathrm{f}_{\mathrm{h}}+\mathrm{f}_{\mathrm{s}}=1\right)$

$$
\begin{gathered}
\tau=\tau_{0}+\alpha \cdot \mathrm{G} \cdot \mathrm{b} \cdot \sqrt{\rho} \\
\mathrm{X}_{\text {intra }}=\mathrm{f}_{\mathrm{h}} \cdot \mathrm{M} \cdot \alpha \cdot \mathrm{G} \cdot \mathrm{b} \cdot\left(\sqrt{\rho_{\mathrm{h}}}-\sqrt{\rho_{\mathrm{s}}}\right), \mathrm{X}_{\text {model }}=\mathrm{X}_{\text {intra }}+\mathrm{X}_{\text {inter }}
\end{gathered}
$$

$\tau_{0}:$ initial friction shear stress

$\alpha$ : constant characteristic of the interactions between the dislocations $(=0.3[15])$

$\mathrm{G}$ : shear modulus $(=78500 \mathrm{MPa})$

$\mathrm{b}:$ Bürgers vector

$\rho, \rho_{\mathrm{h}}, \rho_{\mathrm{s}}$ : total dislocation density, and dislocation densities in the hard and soft phases

$\mathrm{M}$ : mixed Taylor-Sachs factor $(=2.5[16])$

$\mathrm{X}_{\text {intra }}$ has been calculated for $\varepsilon_{\mathrm{p}}=0.046$ et $\varepsilon_{\mathrm{p}}=0.098$. Results are shown in table 3 and compared with the total internal stress predicted by the Lemaittre-Chaboche model $\left(\mathrm{X}_{\text {model }}\right)$. It is also possible to evaluate the intergranular stress $X_{\text {inter }}$ using equation (15). Figure 13 shows consequently the schematic evolution of the three kinds of internal stresses with plastic strain. $\mathrm{X}_{\text {intra }}$ increases more rapidly with plastic strain than the total internal stress. $X_{\text {inter }}$ is consequently dominating at the first stages of the deformation and progressively decreases to zero with plastic strain. This tendancy has previously been observed with a 316L alloy [14].

Table 3: Calculation of the intra/intergranular stresses.

\begin{tabular}{|c|c:c|}
\cline { 2 - 3 } \multicolumn{1}{c|}{} & $\varepsilon_{\mathrm{p}}=0.046$ & $\varepsilon_{\mathrm{p}}=0.098$ \\
\hline$f_{\mathrm{h}}$ & 0.16 & 0.43 \\
$\rho_{\mathrm{s}}\left(\mathrm{cm} . \mathrm{cm}^{-3}\right)$ & $2.2 .10^{10}$ & $2.4 .10^{10}$ \\
\hdashline$\rho_{\mathrm{h}}\left(\mathrm{cm} . \mathrm{cm}^{3}\right)$ & $9.3 .10^{10}$ & $9.6 .10^{10}$ \\
\hdashline $\mathrm{X}_{\text {intra }}(\mathrm{MPa})$ & $\mathbf{3 8} \pm \mathbf{5}$ & $\mathbf{1 0 0} \pm \mathbf{3 5}$ \\
$\mathrm{X}_{\text {model }}(\mathrm{MPa})$ & 135 & 167 \\
\hdashline $\mathrm{X}_{\text {inter }}(\mathrm{MPa})$ & $97 \pm 5$ & $67 \pm 35$ \\
\hline
\end{tabular}

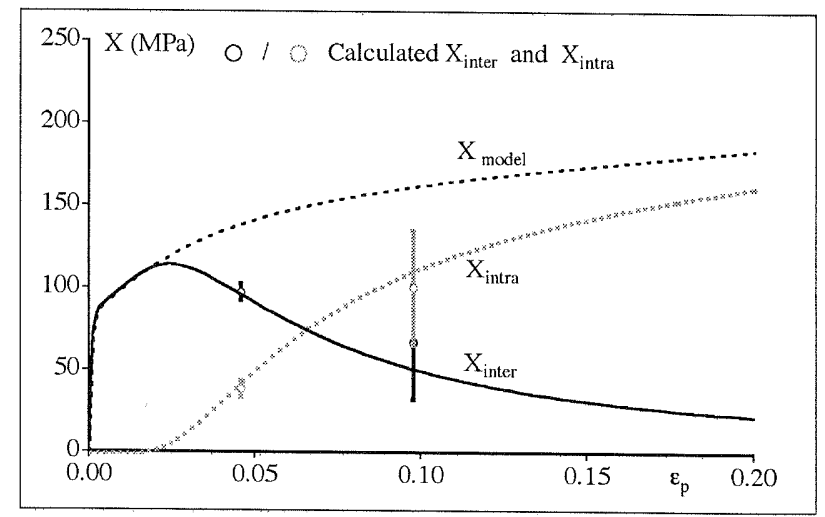

Figure 13: Relative variation of the three kinds of internal stresses with the plastic strain.

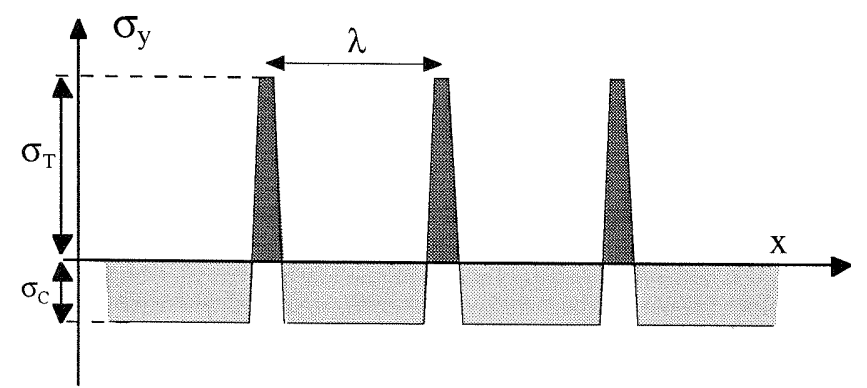

Figure 14: Schematic stress distribution in a strained sample along the tensile direction (y) after unloading.

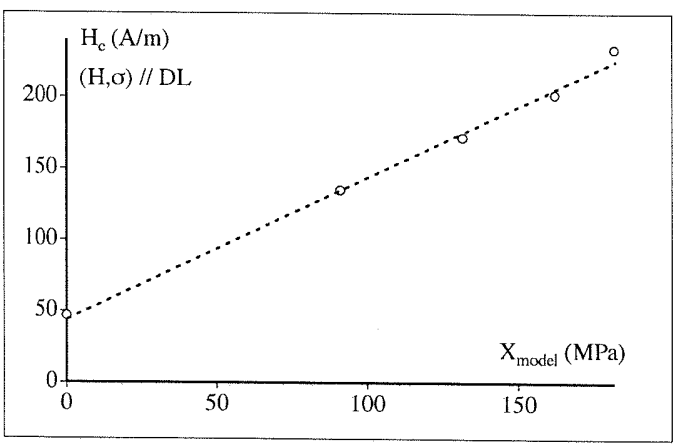

Figure 15: Evolution of the magnetic field strength with $\mathrm{X}_{\text {model }}$ (colinear measurements along $\mathrm{RD}$ ).

Figure 14 shows a schematic diagram of the stress distribution in the cross section of a strained sample following the direction of the applied stress, after unloading. Strong tension areas $\left(\sigma_{\mathrm{T}}\right)$ are counterbalanced 
by much larger areas of weak compression stresses $\left(\sigma_{C}\right)$. This distribution remains the same whatever the plastic strain level. It has been previously observed by B.Cullity with an X-rays method on a comparable SiFe alloy strained at $\varepsilon_{p}=0.032$ [17]. Tension areas are enclosed in the neighbourhood of the grain boundaries at the first stages of the deformation, then in the clusters and tangles at higher plastic strain level. The compressive areas correspond to the average grain volume first, then to the matrix between the clusters or inside the channels. The global wavelength $\lambda$ of the internal stress tends to progressively decrease with increasing plastic strain as it has been discussed by J.Sevillano [18].

\subsection{Analysis of the magnetic behaviour}

The magnetic properties are markedly damaged by plastic strain. This phenomenon is usually correlated to the short range interactions linked to the pinning/unpinning of the magnetic domain walls against the metallurgical defects as dislocation clusters and tangles [19]. Conversely an isotropic distribution of dislocations (for instance at $\varepsilon_{\mathrm{p}}=0.005$ ) should not so much damage the magnetic properties [20]. On the other hand, the internal stresses and the magnetoplastic anisotropy appear from the first stages of the deformation. K.Kashiwaya experimentally verified that a compressive stress strongly decreases the magnetic properties of a comparable alloy [21]. It can also be supposed that the elastic deformations linked to the internal stresses act as an uniaxial macroscopic applied elastic stress. The global compressive stress in the tensile direction after the mechanical unloading consequently induces a strong decrease of the magnetic properties. Moreover a global tensile stress exists in the cross direction (Poisson's effect [22]), and it has been shown that a tensile stress produces a decrease of the magnetic properties, proportionnaly smaller than with the same level of a compressive stress [21],[23]. This could explain the magnetoplastic anisotropy. The degradation of the magnetic properties could also be mainly due to the fields of stress correlated to the internal stresses. The evolution with the plastic strain of the coercive field strength is for example in very good agreement with the evolution of the kinematic strengthening X (Fig. 15). Recent results finally show that the magnetoplastic anisotropy and magnetic degradation are the result of the joint effect of the internal stresses and the magnetostrictive behaviour of the material [4]. This can explain why the magnetoplastic anisotropy is less sensitive when the magnetic measurements are carried out along TD. Supplementary measurements of the anhysteretic curve of the material after the plastic straining confirm these hypothesis [24].

\section{REFERENCES}

[1] O. Hubert and E. Hug, Mat. Science and Tech. 11, (1995) 482-487.

[2] E. Hug, O. Hubert and M. Clavel, IEEE Trans. Magn. 33, (1997) 763-771.

[3] E. Hug, thesis, Université de Technologie de Compiègne, 1993.

[4] O. Hubert, thesis, Université de Technologie de Compiègne, 1998.

[5] E.T. Stephenson, J. Appl. Phys. 57, (1985) 4226-4228.

[6] A.S. Keh and S. Weissmann, "Deformation substructure in body-centered cubic metals", Electron microscopy and strength of crytals (Interscience publishers, N.Y.-London, 1963), pp 231-300.

[7] J. Lemaître and J.L. Chaboche, Mécanique des matériaux solides (Dunod-Bordas, Paris, 1988), pp 196-239.

[8] P. Pilvin, thesis, Université de Paris VI, 1990.

[9] R.M. Bozorth, Ferromagnetism (D. Van Nostrand Company, N.Y., 1951) pp 595-712.

[10] M.V. Rodriguez and P.J. Ficarola, Scripta Met. 20, (1986) 615-620.

[11] C.K. Hou and S. Lee, IEEE Trans. Magn. 30, (1994) 212-216.

[12] E. Hug and O.Hubert, J. Appl. Phys. 79, (1996) 4571-4573.

[13] H. Mughrabi, Acta Met. 31, (1983) 1367-1379.

[14] X. Feaugas, Acta Met., (1999), submitted.

[15] H. Mughrabi, Mat. Science and Eng. 85, (1987) 15-31.

[16] T. Magnin, J. Driver, J. Lepinoux and L.P. Kubin, Rev. Phys. Appl. 19, (1984) 483-502.

[17] B.D. Cullity, Introduction to magnetic materials (Ed. Addison-Wesley, N.Y., 1972), pp 248-358.

[18] J. Gil Sevillano, "Flow stress and work hardening", Materials Science and Technology - vol.6 (Vol. ed. H.Mughrabi, Weinhheim - N.Y. - Basel - Cambridge, VCH, 1993), pp 19-88.

[19] H.R. Hilzinger, H. Kronmüller, J. Magn. Magnetic Mat. 2, (1976) 11-17.

[20] J. Degauque, Mem. et Etudes Scient. Rev. Métal. 1 (1985), 5-23.

[21] K. Kashiwaya, Jpn. J. Appl. Phys. 31, (1992) 237-250.

[22] R. Langman, NDT international, (1981) 255-262.

[23] C. Gourdin, L. Hirsinger, G. Barbier and R. Billardon, J. Mag. Magnetic Mat. 1-3, (1998) 201-202.

[24] O. Hubert, L. Hirsinger and E. Hug, J. Mag. Magnetic Mat. (1999), to be published. 